Universidad de Lima

Facultad de Derecho

Carrera de Derecho

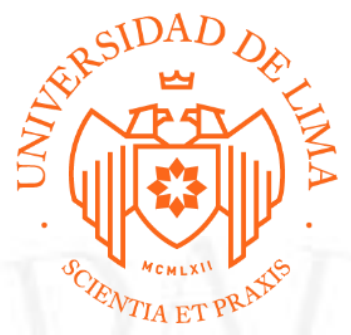

\title{
ARBITRAJE: "ARBITRAJE SOCIETARIO" Y CONCURSAL: "RECONOCIMIENTO DE CRÉDITO"
}

Trabajo de suficiencia profesional para optar el Título Profesional de Abogada

Ana Sofía Restrepo García Calderón

Código 20132441

Lima - Perú

Agosto de 2019 


\section{ARBITRAJE: "ARBITRAJE SOCIETARIO" \\ Materia: Arbitraje Societario \\ $\mathrm{N}^{\mathrm{o}}$ de Expediente: DE - ARBIT0068}

\section{RESUMEN}

El siguiente expediente arbitral versa sobre un conflicto de accionistas que se origina debido a que uno de los accionistas resuelve unilateralmente un pacto de accionistas que estos habían celebrado.

\section{CONCURSAL: "RECONOCIMIENTO DE CRÉDITO"}

Materia: Concursal - Reconocimiento de Crédito

$\mathrm{N}^{\mathrm{o}}$ de Expediente: DE - INDEC0519

\section{RESUMEN}

El siguiente expediente versa sobre un reconocimiento de crédito que se origina por la emisión de A. A. de obligaciones convertibles en acciones, las cuales son adquiridas por el Banco. Este último se presente al procedimiento concursal preventivo de A. A. a solicitar el reconocimiento de dicho crédito. 